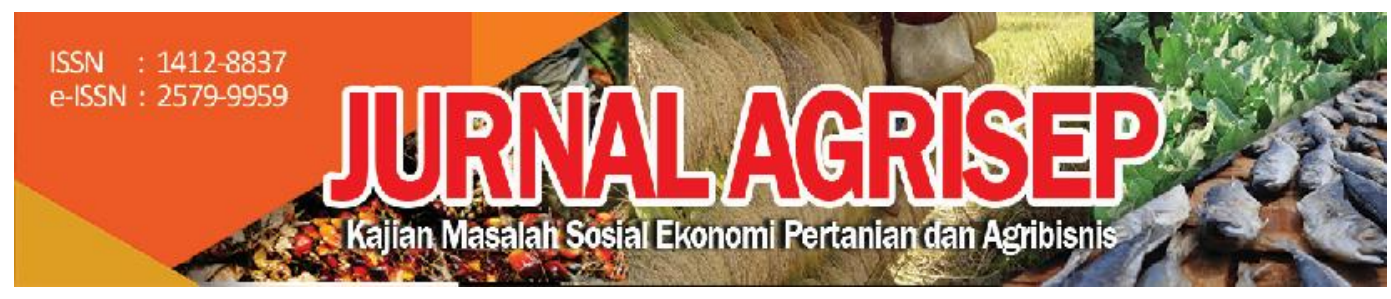

DOI: 10.31186/jagrisep.18.2.279-288

\title{
ROADMAP PENGEMBANGAN KOPI DI KAB. SOLOK SELATAN
}

\author{
Coffee Development Roadmap In Solok Selatan District \\ Yulistriani 区; Yaherwandi; Cindy Paloma \\ Fakultas Pertanian Universitas Andalas \\ Email: yulistrianidarlis87@gmail.com
}

\begin{abstract}
Coffee is an important commodity as a source of foreign exchange and regional income. Solok Selatan district the second largest coffee producer after Solok district in West Sumatra. But the potential for coffee development in Solok Selatan district has not been clearly mapped before. Therefore this study aims is to analyze the potential for coffee development and construct a roadmap for coffee development in Solok Selatan district. This study uses primary and secondary data. For the first purpose, an in-depth interviews were conducted using the purposive sampling method and FGD (Focus Group Discussion) with coffee stakeholders, such as the coffee traders, farmers, agriculture counselor, the government and NGOs (Non-Governmental Organizations). The data, which is a results of interviews and FGDs are grouped into internal and external factors and then analyzed using the SWOT (Strengths-weaknesses-opportunities-threats) analysis to answer the second goal. The analysis results show that the Solok selatan district coffee commodity has potential to be developed because it have a unique flavor of lemon and casiavera. It is necessary to do several stages to develop of Solok Selatan coffee, namely product diversifications, build a coffee center outlets, and design an attractive coffee tourism areas. Thus, the existing potential is expected to develop optimally and Solok Selatan district can be known as one of the "coffee village" in West Sumatra.
\end{abstract}

Keywords : coffee, roadmap, potential, development.

\section{ABSTRAK}

Kopi merupakan komoditi penting sebagai sumber devisa dan pendapatan daerah. Solok Selatan merupakan Kabupaten penghasil kopi kedua terbesar setelah kabupaten Solok di Sumatera Barat. Potensi pengembangan kopi di Kab. Solok Selatan belum dipetakan secara jelas. Penelitian ini bertujuan untuk menganalisa potensi 
pengembangan kopi di Kab. Solok Selatan dan merancang roadmap pengembangan kopi di Kab. Solok Selatan. Penelitian ini menggunakan data primer dan sekunder. Untuk tujuan pertama dilakukan wawancara mendalam menggunakan metode purposive sampling dan FGD (Focus Group Discussion) bersama pelaku usaha kopi, petani, penyuluh, pemerintah dan NGO (Non-Governmental Organization). Data-data, hasil wawancara dan FGD di kelompokan dalam faktor internal dan eksternal kemudian di analisa dengan menggunakan analisa SWOT (Strengths-weaknesses-opportunitiesthreats) untuk menjawab tujuan kedua. Hasil analisis menunjukkan bahwa komoditi kopi Solok Selatan potensial untuk dikembangkan karena mempunyai keunikan citarasa khas lemon dan casiavera. Perlu dilakukan beberapa tahapan untuk pengembangan kopi Solok Selatan yaitu diversifikasi produk, pengadaan sentra outlet kopi, penyajian kawasan wisata kopi yang menarik. Dengan demikian diharapkan potensi yang ada berkembang dengan optimal dan Kab. Solok Selatan dapat dikenal sebagai salah satu wisata kampung kopi di Sumatera Barat.

Kata kunci: kopi, roadmap, potensi, pengembangan.

\section{PENDAHULUAN}

Direktorat Jenderal Perkebunan 2015-2019 menempatkan komoditas kopi menjadi salah satu komoditas yang menjadi sasaran pokok sub agenda prioritas peningkatan agroindustri yaitu peningkatan produksi komoditas andalan dan prospektif ekspor serta mendorong perkembangan agroindustri di pedesaan, selain komoditas kelapa sawit, kakao, teh dan kelapa (Direktorat Jenderal Perkebunan, 2015).

Kopi adalah komoditas perkebunan yang peranannya dalam perekenomian nasional sangat penting. Enam kontribusi komoditas kopi terhadap ekonomi nasional, yaitu: sebagai sumber devisa negara, pendapatan petani, penciptaan lapangan kerja, pembangunan wilayah, pendorong agribisnis dan agroindustri, dan pendukung konservasi lingkungan. Indonesia adalah penghasil kopi terbesar ketiga di dunia setelah Brasil dan Vietnam (Sudjarmoko, 2013).

Luas lahan kopi Sumatera Barat pada tahun 2015 mencapai 42.925 Ha dengan jumlah produksi 34.056 ton. Data tersebut terdiri dari $42.022 \mathrm{Ha}$ perkebunan rakyat dan 903 perkebunan swasta dengan jumlah produksi 33.579 ton perkebunan rakyat dan 480 ton perkebunan swasta (Direktorat jenderal perkebunan, 2016). Di lihat dari data tersebut, perkebunan rakyat mendominasi perkembangan kopi di Sumatera Barat.

Solok Selatan merupakan kabupaten pengasil kopi kedua terbesar di Sumater Barat (Dirjen Perkebunan, 2016). Produksi kopi di Solok Selatan mencapai 1.760 ton pada tahun 2016 (BPS Solok Selatan, 2017). Potensi kopi di Kab. Solok Selatan tersebar di 7 kecamatan dengan luas areal terluas terletak di Kec. Sangir Jujuan disusul Kec. Pauh Duo. Sekitar 787 orang petani kopi tersebar di Kec. Sangir jujuan dan 782 di Kec. Pauh Duo. Kopi merupakan sumber 
pendapatan masyarakat di Kab. Solok Selatan. Potensi pengembangan kopi di Kab. Solok Selatan belum dipetakan secara jelas sehingga belum terlihat arah kebijakan yang harus dilakukan oleh pemerintah bersama petani dan pengusaha kopi di Kab. Solok Selatan. Kopi merupakan komoditi ekspor yang mempunyai prospek cukup baik untuk dikembangkan. Dari uraian di atas maka perlu dilakukan penelitian "Roadmap Pengembangan Kopi di Kab. Solok Selatan".

\section{METODE PENELITIAN}

Metode penelitian ini adalah deskriptif kualitatif. Menurut Nazir (2005), metode deskriptif adalah pencarian fakta dengan interpretasi yang tepat. Tujuan dari penelitian deskriptif ini adalah untuk membuat deskripsi, gambaran atau lukisan secara sistematis, faktual dan akurat mengenai faktafakta, sifat-sifat serta hubungan antar fenomena yang diselidiki. Penelitian kualitatif pada dasarnya merupakan suatu proses penyidikan, mirip pekerjaan detektif yang secara meyakinkan dikemukakan oleh Douglas (1976) di dalam Lisa (2010). Kita dapat membuat pengertian fenomena sosial secara bertahap, kemudian melaksanakannya, sebagian besar dengan cara mempertentangkan, membandingkan, mereplikasi, menyusun katalog, dan mengklasifikasi objek suatu kajian. Pada dasarnya semua itu merupakan kegiatan penarikan sampel, yaitu usàha menemukan keseragaman dan sifat umum dunia sosial, dan kegiatan dilakukan terus dan berulang oleh peneliti lapangan kualitatif.

Penelitian ini di lakukan dari bulan Juni sampai dengan November 2018 di Kab. Solok Selatan menggunakan data primer dan sekunder. Data primer dikumpulkan melalui wawancara responden sebanyak 20 responden petani, 4 orang pedagang pengumpul dan 4 orang pelaku agroindustri kopi yang di pilih melalui metode purposive random sampling. Disamping itu dilakukan FGD (Focus Group Discussion) bersama 15 orang responden (stakeholder pengembangan kopi di Kab. Solok Selatan) yang terdiri dari pelaku usaha kopi, petani kopi, ahli roasting, penyuluh, Dinas Pertanian, Badan Pusat Statistik dan NGO (Non-Governmental Organization). Data sekunder diperoleh melalui studi literatur di perpustakaan, BPS, Dinas Perkebunan dan Kehutanan Kab. Solok Selatan, Dinas Perkebunan Provinsi Sumbar, dan instansi lainnya yang terkait dengan penelitian ini.

Untuk menjawab tujuan pertama data-data hasil wawancara dan studi literatur di deskripsikan untuk menggambarkan potensi. Untuk tujuan kedua data-data dan informasi dikelompokan dalam faktor internal (kekuatan dan kelemahan) dan eksternal (peluang dan ancaman), kemudian dilanjutkan dengan analisis SWOT dan perancangan roadmap pengembangan komoditi kopi. 


\section{HASIL DAN PEMBAHASAN}

\section{Gambaran Umum Daerah Penelitian}

Secara astronomis, Kabupaten Solok Selatan terletak antara $01^{0} 17^{\prime} 13^{\prime}-01^{0}$ 46 45" Lintang Selatan dan $100^{\circ} 53^{\prime} 24^{\prime \prime}$ - 1010 26' 27" Bujur Timur. Kabupaten Solok selatan mempunyai luas wilayah sekitar 3.346,20 Km2 . Kabupaten Solok Selatan berbatasan langsung dengan Kabupaten Solok, Provinsi Jambi, Kabupaten Pesisir Selatan, dan Kabupaten Dharmasraya.

Kabupaten Solok Selatan mempunyai 7 kecamatan dengan Kecamatan Sangir Balai Janggo memiliki wilayah terluas, yaitu $686,94 \mathrm{Km} 2$ atau sekitar 20,52 \% dari luas Kabupaten Solok Selatan. Sedangkan Kecamatan Sangir Jujuan memiliki luas daerah terkecil, yakni 278,06 Km2 atau sekitar 8,3 \% dari luas Kabupaten Solok Selatan. Ketinggian rata-rata Kab. Solok Selatan berkisar antara 300-950 mdpl.

\section{Potensi Kopi Solok Selatan}

Di dalam penelitian ini potensi kopi di lihat dari beberapa aspek, yaitu; luas lahan, jumlah produksi dan jumlah petani kopi di Kab. Solok Selatan. Perkembangan luas lahan dapat di lihat pada tabel 1 sebagai berikut:

Tabel 1. Perkembangan Luas Lahan dan Produksi Perkebunan Kopi di Kab. Solok Selatan

\begin{tabular}{cccc}
\hline No & Tahun & Luas Lahan $(\mathrm{Ha})$ & Produksi (Ton) \\
\hline 1. & 2012 & 3.262 & 1.268 \\
2. & 2013 & 3.241 & 1.346 \\
3. & 2014 & 3.223 & 1.742 \\
4. & 2015 & 3.232 & 1.625 \\
5. & 2016 & 3.256 & 1.760 \\
\hline
\end{tabular}

Dari data di atas dapat di lihat bahwa luas lahan tahun 2012 seluas 3.262 Ha lahan perkebunan Kopi di Kab. Solok Selatan mengalami penurunan menjadi 3.241 Ha (2013) dan terus turun menjadi 3.223 Ha (2014), namun mulai meningkat kembali pada tahun 2015 menjadi 3.232 Ha dan 3.256 Ha pada tahun 2016. Dari pengamatan di lapangan di dapatkan informasi dari informan kunci bahwa siklus ini terjadi karena pada awalnya masyarakat beralih ke tanaman kelapa sawit yang dianggap lebih menjanjikan. Namun seiring dengan terjadinya peningkatan permintaan kopi Indonesia di dunia dan kebijakan secara nasional terhadap komoditas kopi. Pemerintah kabupaten juga mulai memperhatikan peningkatan potensi kopi di Kab. Solok Selatan melalui pemberian bantuan bibit kopi kepada beberapa kelompok tani. Masyarakat kembali menanam dan merawat tanaman kopi, sehingga kopi menjadi prioritas untuk di kembangkan. 
Produksi kopi Solok Selatan dari tahun 2012 hingga tahun 2016 terus meningkat. Hal ini mengindikasikan bahwa walaupun terjadi menurunan luas lahan pada tahun 2013 hingga tahun 2015, namun tidak mempengaruhi jumlah produksi kopi secara signifikan. Peningkatan luas lahan jika diiringi dengan perawatan yang baik dan kondisi agroklimat yang sesuai akan meningkatkan produksi. Produksi kopi di Kab. Solok Selatan dapat di lihat pada Tabel 1.

Kopi merupakan salah satu komoditi unggulan dan sumber pendapatan masyarakat di Kab. Solok Selatan. Sekitar 2.788 KK mengusahakan tanaman kopi robusta dan 97 KK kopi Arabica (BPS Solok Selatan, 2017). Luas lahan terluas terdapat pada Kec.Sangir jujuan sebesar $827 \mathrm{Ha}$, akan tetapi produksi tertinggi terdapat pada Kec. Pauh Dua sebesar 443,794 ton. Data selengkapnya dapat di lihat pada Tabel 2 sebagai berikut:

Tabel 2. Luas lahan dan Produksi Kopi di Kab. Solok Selatan per Kecamatan tahun 2016

\begin{tabular}{clcc}
\hline No. & \multicolumn{1}{c}{ Kecamatan } & Luas Lahan (Ha) & $\begin{array}{c}\text { Jumlah Produksi } \\
\text { (ton) }\end{array}$ \\
\hline 1. & Sangir & 308 & 167,611 \\
2. & Sangir Jujuan & 827 & 427,092 \\
3. & Sangir Balai Janggo & 173 & 103,185 \\
4. & Sangir Batang Hari & 596 & 345,209 \\
5. & Sungai Pagu & 249 & 136,631 \\
6. & Pauh Duo & 814 & 443,794 \\
7. & Koto Parik Gadang Diateh & 289 & 136,478 \\
\hline \multicolumn{2}{c}{ Total } & 3.256 & $1.760,000$ \\
\hline
\end{tabular}

Selain faktor luas lahan dan produksi, potensi kopi Solok Selatan juga digambarkan oleh jumlah petani yang mengusahakan tanaman kopi. Dari data statistik di dapatkan gambaran bahwa petani kopi robusta mengalami penurunan, namun kopi Arabica yang sebelumnya belum ada di tahun 2015 dan 2016 mulai muncul. Hal ini terjadi karena kopi Arabica sudah mulai di lirik oleh petani karena mempunyai prospek yang baik untuk dikembangkan dan merupakan kopi yang disukai oleh pasar internasional. Arabica mempunyai citarasa yang lebih khas di bandingkan dengan robusta. Dan Arabica hanya dapat tumbuh dengan baik pada daerah dengan ketinggian lebih dari $1000 \mathrm{mdpl}$. Faktor ini menjadi penghambat untuk pengembangan Arabica di Kab. Solok Selatan, karena wilayah yang mempunyai ketinggian yang cocok dengan tanaman kopi Arabica terbatas yaitu di Kec. Sangir. Perkembangan jumlah petani kopi di Kab. Solok Selatan lebih lengkapnya dapat dilihat pada Tabel 3. 
Tabel 3. Jumlah Petani Kopi di Kab. Solok Selatan tahun 2012-2017

\begin{tabular}{cccc}
\hline \multirow{2}{*}{ No } & Tahun & \multicolumn{2}{c}{ Jumlah Petani } \\
\cline { 3 - 4 } & 2012 & Robusta & Arabica \\
\hline 1. & 2013 & 2.836 & - \\
2. & 2014 & 2.608 & - \\
3. & 2015 & 2.793 & - \\
4. & 2016 & 2.793 & 36 \\
5. & 2.788 & 41 \\
\hline
\end{tabular}

Pada tahun 2017 terdapat 7 agroindusrti kopi bubuk di Kab. Solok Selatan. Agoindustri tertua di Solok Selatan adalah agroindustri kopi janggut yang berada di Sungai lambai Kec. Sangir berdiri tahun 1930. Dari 7 agroidustri kopi di Kab. Solok Selatan menyerap sekitar 33 orang tenaga kerja. Nilai produksi total dari ketujuh agroindustri sebesar Rp. 643.500.000.- (BPS Solok Selatan, 2017).

Produk olahan kopi Solok Selatan masih terbatas dalam bentuk kopi bubuk dan kopi biji matang (roasted coffee). Jenis diversifikasi produk kopi meliputi kopi bubuk, kopi instan, kopi biji matang (roasted coffee), kopi tiruan, kopi rendah kafein (decaffeinated coffee), kopi mix, kopi celup, ekstrak kopi, minuman kopi dalam botol dan produk turunan lainnya (Kementerian Pertanian, 2016). Solok Selatan perlu melakukan diversifikasi produk olahan kopi sehingga dapat memperluas pasar. Potensi pengembangan produk olahan kopi dapat digambarkan oleh diagram pohon industri kopi pada Gambar 1.

Di lapangan di temukan bahwa perkembangan agroindustri kopi di Kab. Solok Selatan mulai menunjukan peningkatan. Hal ini di dukung dengan munculnya agroindustri-agroindustri baru tahun 2018. Namun potensi ini belum terpetakan dengan jelas, pemetaan potensi selanjutnya akan di gambar dalam Roadmap pada poin 2.

\section{Roadmap Pengembangan Kopi Di Kab. Solok Selatan}

Dari hasil survey dan wawancara di lapangan maka di kelompokkan faktor internal dan eksternal yang mempengaruhi pengembangan kopi di Kab. Solok Selatan sebagai berikut:

\section{Faktor Internal dan Eksternal}

Berdasarkan hasil observasi peneliti dan hasil wawancara serta FGD, maka ditemukan faktor-faktor internal dan eksternal dalam Pengembangan Kopi di Kabupaten Solok Selatan adalah sebagai berikut: 


\section{Kekuatan (Strenghts)}

1. Keberadaan Agroklimat yang Sesuai untuk Pengembangan Kopi karena solok selatan berada pada ketinggian berkisar antara 300-950 mdpl.

2. Kopi Solok Selatan punya citarasa khas casiavera dan lemon.

3. Dari segi kelembagaan, telah terbentuk Asosiasi Pelaku Usaha Kopi Solok Selatan pada tanggal 24 Juli 2018.

4. Dari sisi ketersediaan SDM, telah tersedia Barista dan ahli roasting di Kab. Solok Selatan.

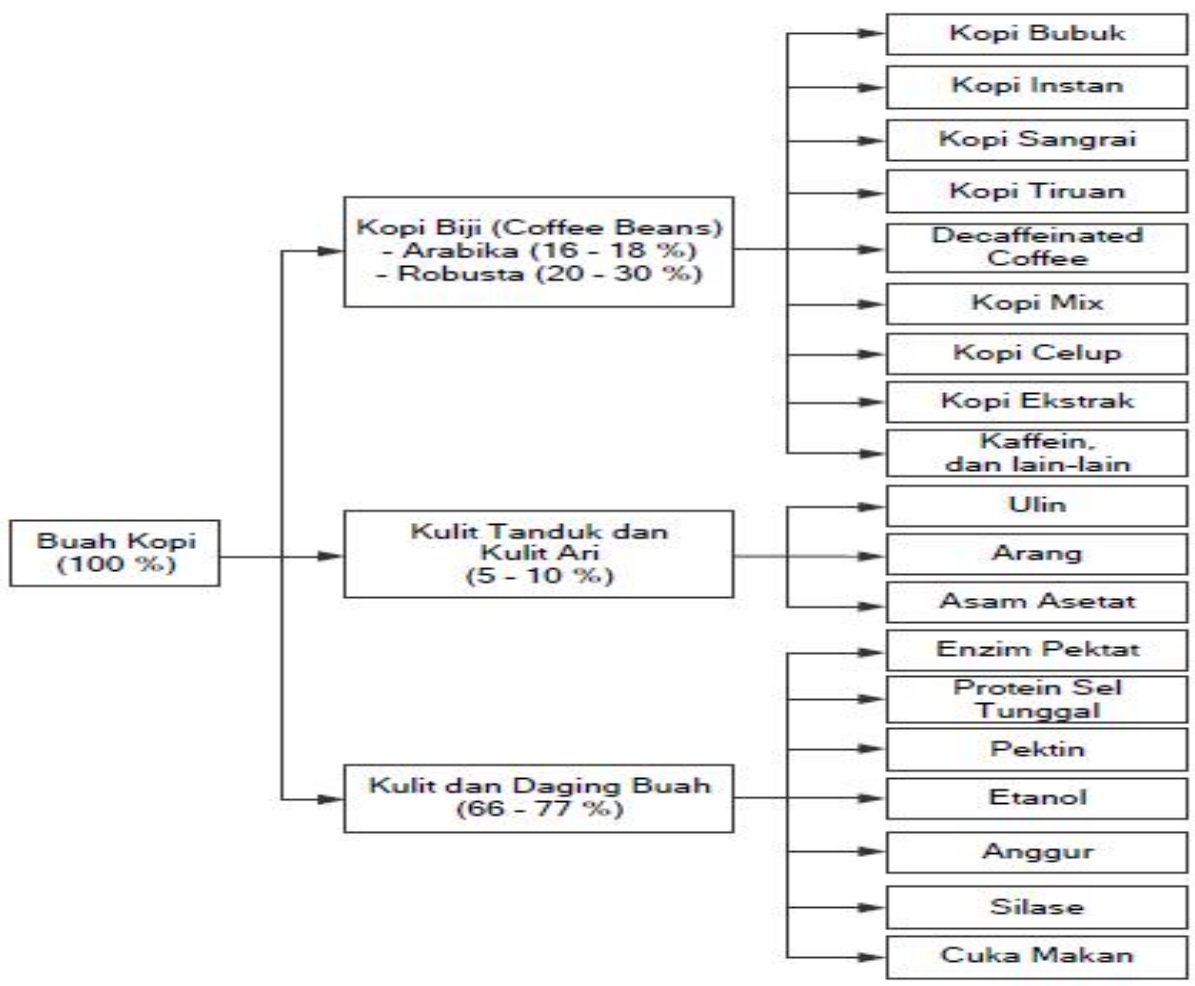

Gambar 1.

Pohon Industri Kopi (Departemen Perindustrian, 2009)

\section{Kelemahan (Weaknesses)}

1. Kurangnya pengetahuan petani akan cara panen yang baik yang berpengaruh terhadap kualitas kopi.

2. Belum ada outlet kopi yang terpusat pada satu kawasan.

3. Kopi Solok Selatan di jual ke daerah lain dalam bentuk berasan (green bean) dengan harga relative lebih rendah dan lebih dikenal dengan merk daerah pengolahnya. 
4. Belum semua usaha kopi bubuk di Solok Selatan berlabel halal MUI dan terdaftar di BPPOM.

5. Belum ada koperasi sebagai lembaga penunjang dalam pengembangan kopi di Kab. Solok Selatan.

\section{Faktor-faktor Eksternal}

\section{Peluang (Opportunities)}

1. Otonomi Daerah.

2. Peluang pasar yang masih terbuka baik domestik maupun luar negeri.

3. Adanya dukungan pemerintah dalam pemberian bantuan bibit dan peralatan bagi petani dan pelaku usaha kopi.

\section{Ancaman (Threats)}

1. Munculnya Produk-Produk Kopi dari Wilayah Lain.

2. Fluktuasi harga kopi.

3. Bantuan alat yang diberikan pemerintah tidak digunakan dan tidak cocok kebutuhan petani.

\section{Hasil Analisis SWOT}

Hasil analisis matriks SWOT didapatnya beberapa strategi priotitas dalam pengembangan kopi di Kabupaten Solok Selatan. Strategi prioritas ini terdiri dari:

1. Dengan adanya produk kopi dari daerah lain maka pelaku usaha kopi Solok Selatan perlu melakukan inovasi melalui diversifikasi produk olahan kopi Solok Selatan.

2. Pelatihan kepada petani kopi terkait dengan pengelolaan kebun kopi yang baik mulai dari proses pemilihan bibit sampai proses panen.

3. Pemahaman kepada petani bahwa aktivitas panen sesuai standar (panen merah) akan berpengaruh terhadap kualitas dan citarasa kopi yang dihasilkan.

4. Pelatihan kepada petani dan pelaku usaha terkait dengan pengolahan pasca panen kopi sehingga kopi Solok Selatan tidak lagi dijual ke luar daerah dalam bentuk bahan mentah/berasan (green bean).

5. Memperpendek rantai pemasaran kopi sehingga harga yang diperoleh petani dapat lebih tinggi dari sebelumnya.

6. Menyediakan sarana dan prasarana penunjang dalam pengembangan agrowisata kopi baik sarana transportasi maupun akomodasi dan fasilitas agrowisata lainnya.

7. Memberikan pelatihan kepada petani, pelaku usaha dan stakeholder terkait bagaimana menyiapkan paket-paket wisata agro di Kabupaten Solok Selatan sehingga konsumen (wisatawan) dapat memperoleh 
kepuasan tersendiri dengan penyajian paket-paket wisata Solok Selatan yang didukung dengan objek-objek wisata lainnya.

8. Memberdayakan asosiasi kopi Solok Selatan sebagai wadah belajar bersama tentang kopi baik penyuluh, pelaku usaha dan petani kopi sehingga produk kopi Solok Selatan selalu berinovasi dan lebih dikenal oleh pasar

9. Promosi produk olahan kopi Solok Selatan dengan berbagai media promosi.

10. Merangkul seluruh pelaku usaha kopi untuk membuat produk olahan kopi Solok Selatan berlabel halal MUI dan terdaftar di BPPOM serta paten kopi Solok Selatan untuk menjaga kepercayaan konsumen.

11. Membentuk koperasi yang merangkul seluruh pengusaha termasuk petani kopi sehingga dapat meningkatkan kemampuan petani dan pengusaha dalam akses modal.

Dari gambaran potensi kopi dan pengelompokkan ke dalam faktor internal dan eksternal kemudian di lanjutkan dengan analisa SWOT dan perancangan roadmap pengembangan kopi di Kab. Solok Selatan sebagai berikut:

Tabel 4. Roadmap pengembangan Kopi Solok Selatan

\begin{tabular}{|c|c|}
\hline Kondisi saat ini & $\begin{array}{l}\text { Kondisi yang diharapkan } 6 \text { tahun ke } \\
\text { depan 2019-2025 }\end{array}$ \\
\hline $\begin{array}{l}\text { Potensi: } \\
\text { Luas lahan } 3.256 \text { Ha dengan } \\
\text { jumlah produksi } 1.760 \text { ton/th dan } \\
7 \text { agroindustri yang sedang } \\
\text { berkembang didukung oleh } \\
\text { adanya asosiasi kopi Solok } \\
\text { Selatan. }\end{array}$ & $\begin{array}{l}\text { Menumbuhkan agroindustri melalui: } \\
\text { a) diversifikasi produk } \\
\text { b) outlet-outlet olahan kopi } \\
\text { c) Pembentukan koperasi } \\
\text { d) penyajian wisata kopi yang } \\
\text { menarik }\end{array}$ \\
\hline 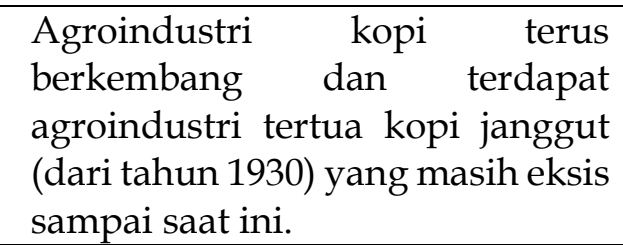 & $\begin{array}{l}\text { Peningkatan PAD melalui } \\
\text { pengembangan agroindustri berbasis } \\
\text { agrowisata kampung kopi }\end{array}$ \\
\hline
\end{tabular}

\section{SIMPULAN DAN SARAN}

\section{Simpulan}

Dari hasil penelitian dapat disimpulkan bahwa potensi pengembangan kopi di Kab. Solok Selatan cukup besar dilihat dari aspek luas lahan, jumlah produksi, petani dan agroindustri. Kehadiran asosiasi kopi Solok Selatan dapat menjembatani aspirasi dari masing-masing stakeholder dalam pengembangan 
kopi di Solok Selatan. Roadmap pengembangan kopi menjadi gambaran pengambangan potensi kopi Solok Selatan secara umum.

\section{Saran}

Perlu dilakukan beberapa tahapan untuk pengembangan kopi Solok Selatan yaitu diversifikasi produk, pengadaan sentra outlet kopi, penyajian kawasan wisata kopi yang menarik. Sehingga potensi yang ada dapat termanfaatkan dengan optimal. Dengan pengoptimalan potensi diharapkan akan meningkatkan pendapat petani, pelaku usaha dan pendapatan daerah secara keseluruhan. Pengembangan kawasan agrowisata kopi dapat menjadi salah satu agenda penting untuk pengembangan kopi di Solok Selatan.

\section{DAFTAR PUSTAKA}

Badan Pusat Statistik Kab.Solok Selatan. 2017. Solok Selatan Dalam Angka. Badan Pusat Statistik. Solok Selatan.

Depatemen Perindustrian. 2009. Roadmap Industri Pengolahan Kopi. Direktorat Jenderal Industri Agro dan Kimia Departemen Perindustrian. Jakarta.

Direktorat Jenderal Perkebunan. 2015. Statistik Perkebunan Kopi Indonesia.

Direktorat Jenderal Perkebunan Kementerian Perkebunan. Jakarta. 2016. Statistik Perkebunan Indonesia 2015-2017. Direktorat Jenderal Perkebunan Kementerian Perkebunan. Jakarta.

Kemeterian Pertanian. 2016. Outlook Kopi, Komoditas Pertanian Subsektor Pertanian. Pusat Data dan Sistem Informasi Pertanian Sekretariat Jenderal - Kementerian Pertanian. Jakarta.

Lisa, Ridvia, Maschandra dan Rusman Iskandar. 2010. Analisis Data Kualitatif Model Miles dan Huberman (sebuah rangkuman dari buku Analisis Data Qualitatif, Mathew B. Miles dan A. Michael Huberman) Terjemahan Tjetjep Rohindi Rodidi, UI-Press 1992. Program Magister Pendidikan Kejuruan Fakultas Teknik Universitas Negeri Padang

Nazir, M. 2005. Metode Penelitian. Ghalia Indonesia. Jakarta.

Sudjarmoko. B. 2013. Peluang dan Tantangan Pasar Kopi Indonesia di Pasar Domestik dan Pasar Internasional. Media Komunikasi Tanaman Industri dan Penyegar. Pusat Penelitian dan Pengembangan Perkebunan. Bogor. Volume 1 (2). Februari 2013. 